\title{
Peningkatan Kognitif melalui Literasi Numerik dan Saintifik dengan Metode Atik pada Kegiatan Cat Air di TK Mutiara Lebah
}

\author{
Anne Gracia RK ${ }^{1}$ Sri Watini ${ }^{2}$ \\ 1,2Universitas Panca Sakti Bekasi, Indonesia \\ E-mail: annegracia.alc@gmail.com, srie.watini@gmail.com
}

\begin{tabular}{l} 
Article Info \\
\hline Article History \\
Received: $2021-12-27$ \\
Revised: $2022-02-02$ \\
Published: $2022-02-18$
\end{tabular}

Published: 2022-02-18

Keywords: Early Childhood;

Watercolor;

Cognitive;

ATIK Method.

\begin{abstract}
Carrying out activities that contain a comprehensive stimulus will provide an opportunity for early childhood to experience maturation of cognitive skills, with the ATIK learning model. The choice of the ATIK model for activities with watercolors which is to stimulate numerical and scientific literacy is a strategic step to improve children's cognitive at an early age. Descriptive research method is a fact-finding with the right interpretation with systematic, factual, and accurate data collection that looks at the relationship between phenomena. Data collection techniques are carried out using observation and visual documentation in the form of images. ATIK Model (Observe-Imitate-Work) which was carried out as a learning stage through activities with watercolors in early childhood at Mutiara Lebah Kindergarten showed the results of increasing numeracy and science literacy skills to encourage children's cognitive abilities to move to the next level of education.The ATIK model became an option in early childhood learning activities for to reach the stage of ability at every age level. It is important for teachers to apply the ATIK model at the initial stage of understanding the model for each concept that will be given to students.
\end{abstract}

\begin{tabular}{l}
\hline Artikel Info \\
\hline Sejarah Artikel \\
Diterima: $2021-12-27$ \\
Direvisi: 2022-02-02 \\
Dipublikasi: $2022-02-18$
\end{tabular}

Kata kunci: Anak Usia Dini; Cat Air;

Kognitif;

Metode ATIK

\section{PENDAHULUAN}

Masa usia dini adalah periode penting dalam kehidupan manusia, dalam jurnal Sri Watini 2020 disampaikan karakteristik anak di usia dini sangat spesifik dengan aktivitas meniru dan mengenali dunia sekitarnya. Sebab itu sangat diperlukan metode yang memberi contoh dengan benar dan sistematis untuk mendukung proses perkembangannya. Studi pada TK Mutiara Lebah Bekasi menggunakan Model belajar ATIK yang didaftarkan oleh Sri Watini pada HKI Kemenhumkam dengan nomor pencatatan 000229956 pada tanggal 28 Januari 2018 di Kota Bekasi, Jawa Barat, sebagai sistematika stimulus pada anak TK A dan TK B. Melakukan kegiatan yang mengandung stimulus komprehensif akan mem- beri kesempatan anak usia dini mengalami pematangan pada keterampilan kognitif. Kegiatan yang dipilih adalah mencairkan cat untuk mendapat warna yang lebih muda serta mencampurkan dua warna cat. Proses pencairan cat akan dilakukan dengan memberi air dengan proses menghitung tetesan sebagai kombinasi stimulus untuk memberi pengalaman literasi numerik. Literasi numerasi adalah stimulus pembentukan komponen keterampilan kognitif melalui proses visual koordinasi mata tangan pada simbol yang memicu atensi keteraturan urutan. (Douglas, 2018), Model ATIK memiliki komponen:

1. Amati merupakan suatu proses kegiatan untuk melihat atau memperhatikan suatu 
objek, kejadian atau peristiwa yang ada di sekitarnya. Amati merupakan kata dasar dari mengamati ataupun pengamatan, dalam pendidikan anak usia dini pengama-tan adalah hal yang paling penting dalam kehidupan anak

2. Tiru suatu kemampuan melakukan kem-bali perilaku yang dicontohkan. Anak akan melakukan peniruan atau imitasi pada apa yang dilihat, didengar dan dirasakan. Peniruan dalam tahapan kon-septual dapat membentuk pengertian, karena dengan perilaku imitasi di mana anak sebelumnya tidak mengerti dan sete-lah anak melakukan perilaku imitasi anak mulai mengerti

3. Kerjakan dengan mengerjakan sesuatu maka seseorang akan mendapatkan suatu keterampilan, pengetahuan dan pengalaman dari suatu peristiwa atau kejadian.

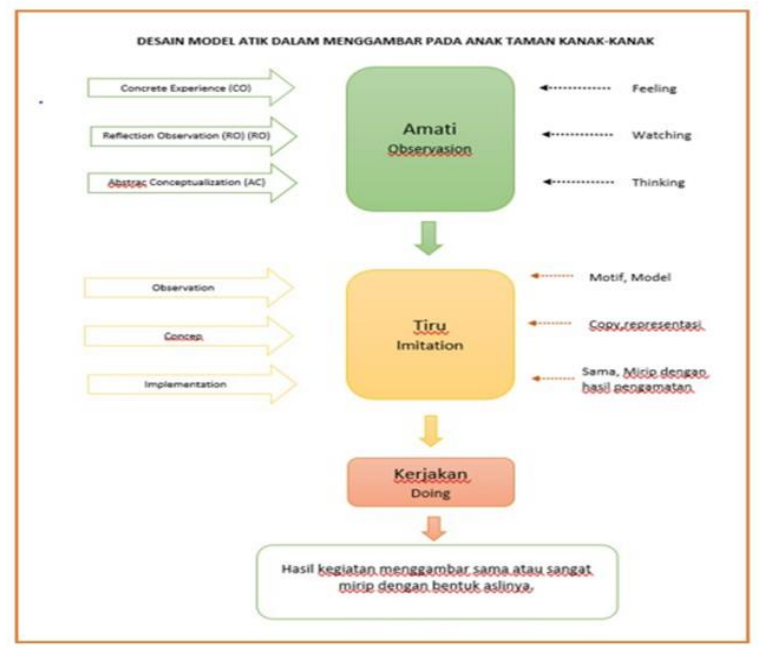

Gambar 1. Konsep Model ATIK

(Sri Watini, 2021)

(Haim Eshach, Science Literacy in Primary schools and pre-schools) menyatakan bahwa sains adalah kompilasi fakta dan bentuk, sains bukan proses rumit penelitian dengan formula yang kompleks pada awalnya. Melakukan proses sains membuat manusia mencari penyebab serta penjelasan yang rasional, mengurangi bobot emosi dan perkiraan intuitif, dengan tersedianya fakta maka proses menduga kemunculan peristiwa akan berbasis memori data dan informasi yang terstruktur. Pengalaman yang terjadi pada anak usia dini menjadi koleksi memori fakta yang akan direkam dan ikut dalam proses imajinasi perencanaan serta perkiraan kemunculan peristiwa berikutnya. Melalui aktivitas dengan media cat air akan terjadi pengambilan data identifikasi warna yang akan menjadi pengalaman untuk menemukan kombinasi warna dengan pengala- man pencairan. Pertemuan warna yang berbeda menambah stimulus pencarian pengalaman dengan tantangan meniru gambar atau situasi sekitar, pengalaman anak bermain cat air dengan kuas akan menambah fakta perubahan pada hasil apusan yang secara saintifik memberikan kematangan proses kognitif. Selagi anak mencairkan kepadatan cat dengan menghitung jumlah tetesan air ini akan memberi pengalaman proses hitung berurutan, sekaligus sensasi visual perbedaan gradasi warna.

\section{METODE PENELITIAN}

Metode dalam penelitian ini menggunakan metode penelitian deskriptif yang meneliti kondisi sekelompok manusia, objek, kondisi, sistem pemikiran, atau kilas peristiwa pada masa sekarang. Menurut Nazir, 2005 dalam jurnal Watini, 2019 menyatakan metode penelitian deskriptif merupakan pencarian fakta dengan interpretasi yang tepat dengan pendataan secara sistematis, faktual, dan akurat yang melihat hubungan antar fenomena. Deskriptif kualitatif menyampaikan data-data lengkap, teratur, berjenjang dan berkesinambungan untuk menghasilkan informasi yang valid, dapat dipercaya, otentik dan bisa dibuktikan kebenarannya, teknik pengumpulan data menggunakan pengamatan dan dokumentasi visual berupa gambar.

\section{HASIL DAN PEMBAHASAN}

Meningkatkan kemampuan anak usia dini terhadap literasi sains \& numerasi dengan media cat air mencampurkan dua warna yang berbeda akan menghasilkan warna baru serta kegiatan mencampurkan air dengan menggunakan pipet pada cat dengan jumlah volume air yang berbeda kemudian mengoles cat warna tersebut di atas kertas maka di sini anak menemukan perbedaan gradasi warna. Tujuan dari kegiatan eksplorasi ini adalah untuk peningkatan kemampuan literasi sains dan numerasi pada anak setelah kegiatan permainan warna dengan menggunakan cat air, hasil percobaan diharapkan siswa memiliki kemampuan sains tentang warna dengan kriteria anak tertarik dan merasa senang dalam kegiatan bermain warna, anak mampu mencampur warna dengan baik untuk menghasilkan warna baru serta anak mampu memahami perbedaan gradasi warna dg mencampurkan volume air yg berbeda pada cat warna setelah cat warna tersebut di di oleskan pada kertas. Literasi numerasi yg diperoleh pada kegiatan ini adalah jumlah tetesan air yg berbeda akan menghasilkan gradasi warna yg berbeda. 
Gerakan kuas membentuk apusan yang berbedabeda membangunkan keterampilan 630ias630ic halus dan koordinasi mata tangan yang mendukung terbentuknya atensi untuk keterampilan kognitif.

Media gambar adalah satu media yang 630ias digunakan untuk mengenalkan lingkungan sekitar kepada anak, cara mengajar anak usia diniyang menyenangkan 630ias dilakukan dengan menyisipkan kegiatan menggambar bagi anak. Ketika anak telah 630ias membuat pola garis dan bentuk, ajarkanlah anak untuk menggambarkan apa yang ia lihat. Kegiatan mewarnai dan meng-gambar telah menjadi bagian hidup kanak-kanak sepanjang masa. Salah satu teknik aktivitas mewarnai dapat dilakukan dengan meman-faatkan media cat air dengan metode ATIK untuk memberi kesempatan pengalaman yang meng-hasilkan temuan baru pada pengalaman anak berinteraksi dengan warna dan bentuk apusan. Ada beberapa hal yang harus diperhatikan dalam mempersiapkan media untuk belajar dengan menggunakan cat air yaitu:

1. Pemilihan kertas yang cukup tebal dan tidak mudah robek setelah menyerap air.

2. Pemilihan dan penggunaan brush atau kuas untuk kegiatan melukis khususnya waktu membentuk apusan. Jadi pilihlah jenis kuas yang memiliki tersedia untuk dikenali hasil apusannya, perhatikan rambut kuas berada dalam ikatannya, tidak bercabang. Apusan kuas akan berbeda tergantung jenis ikatan bulu dan penggunaan kuas. Bagian kuas tengah dan ujung akan menghasilkan apusan yang berbeda, ditambah variasi tarikan arah kuas yang ditekan atau ditarik ke ujung kuas.

3. Palet dan air yang berfungsi sebagai wadah untuk menuangkan dan meracik warna.

4. Cat Air, pemilihan warna merupakan hal penting yang perlu diperhatikan karena tidak sedikit mengatakan bahwa warnalah yang menentukan hasil akhir dari suatu lukisan.

Warna primer yaitu Merah, Kuning, Biru sedangkan warna sekunder yaitu Orange, Hijau, Ungu dan Warna tersier terdiri dari Magenta, Cyan dan lainnya. Induk dari 3 warna tersebut adalah Warna Primer, namun ketika mencampur warna primer, maka biasanya akan menghasilkan warna sekunder. Sedangkan ketika mencampur warna sekunder, maka biasanya akan menghasilkan warna tersier, Langkah-langkah Kegiatan yaitu mempersiapkan alat

1. Tiga (3) warna dasar cat pada pertemuan awal, yaitu: merah, kuning, biru.
2. Kuas bulat dan pipih

3. Palet cat

4. Pipet plastik (tidak wajib).

5. Kertas gambar dengan sketsa kotak 2 kolom dan 5 baris.

Tabel 1. Arahan Kegiatan 1

\begin{tabular}{l} 
Arahan Kegiatan \\
\hline $\begin{array}{l}\text { Beri gumpalan 1 warna cat } \\
\text { ukuran sekitar 1mm pada } 5 \\
\text { rongga palet }\end{array}$ \\
\hline
\end{tabular}

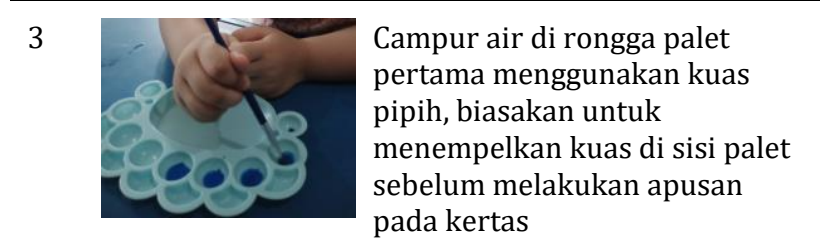

4 Lakukan apusan pada kotak

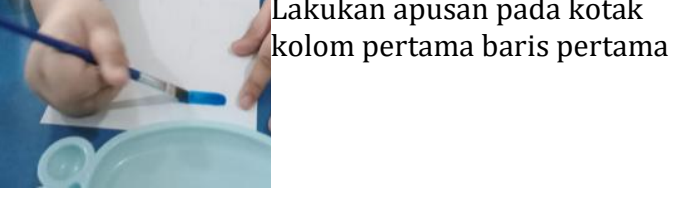

5 Lanjutkan langkah tiga dan

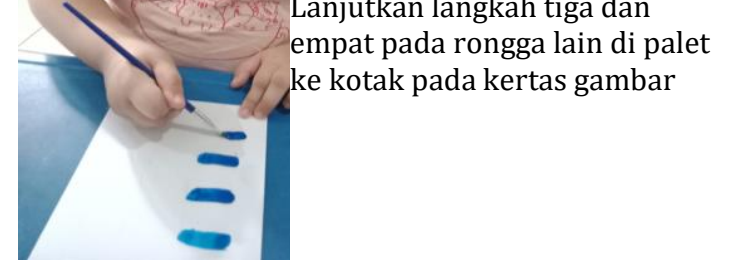

6

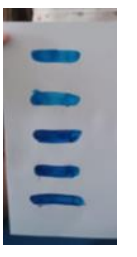

Lakukan diskusi pengamatan perbedaan ketegasan warna yang semakin tebal atau gelap

Tabel 1. Arahan Kegiatan 2

No Arahan Kegiatan


2

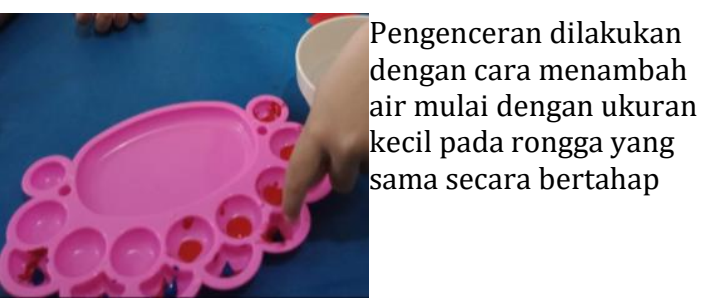

3

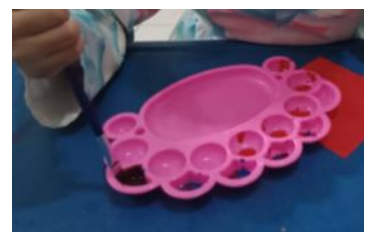

4

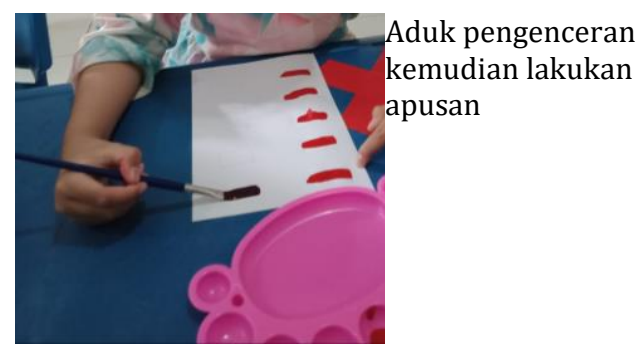

5

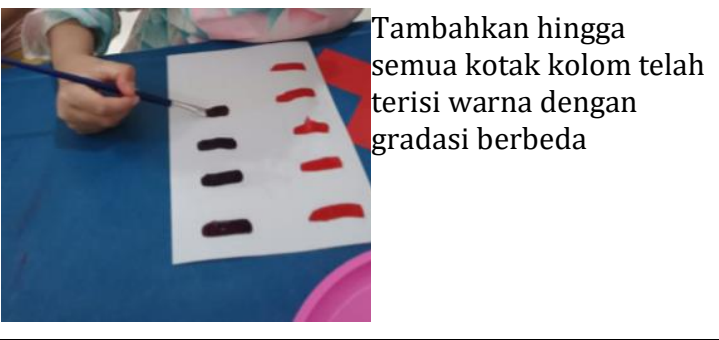

6

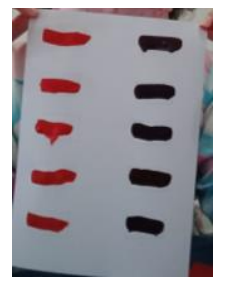

Model ATIK (Amati - Tiru - Kerjakan) yang dilakukan sebagai tahapan pembelajaran melalui kegiatan dengan cat air pada anak usia dini TK Mutiara Lebah menunjukkan hasil kemampuan anak melakukan kegiatan dengan kendali emosi yang baik, dengan keteraturan langkah untuk mengamati arahan dan pijakan guru anak mendapat kesempatan untuk menyimpan memori yang terstruktur sekuens serta melatih atensinya untuk melakukan proses selanjutnya. Pada langkah arahan dan pijakan saat guru menyampaikan cara meneteskan air dengan menghitung jumlah tetesan, anak diminta meniru proses hitung secara verbal, pembiasaan numerasi melalui kegiatan pengamatan yang ditiru tanpa dilakukan akan mengembangkan pola pikir numerikal yang diperlukan untuk kehidupan sehari-hari, oleh Rhonda bahkan disebut sebagai keterampilan "survival" atau menyelamatkan diri. Literasi numerasi merupakan dasar pengambilan keputusan dan proses pikir keseharian pada proses memori pembiasaan keteraturan, dengan langkah meniru dalam model ATIK akan terjadi tahapan tersebut dalam proses pematangan kerja otak. Stimulasi literasi numerik berlangsung dalam suasana gembira, atensi berkembang lebih lanjut pada langkah arahan yang menantang misteri perubahan warna, membuat anak-anak bersemangat untuk melaksanakan kegiatan. Anak kemudian mengikuti langkah tanpa melakukan langsung dan proses ini merupakan momen peniruan virtual yang membangun memori awal dengan baik. Stimulus literasi numerik dan saintifik dengan atensi pada rentang waktu selama proses arahan hingga pelaksanaan kegiatan akan meningkatkan keterampilan kognitif anak usia dini.

Pada tahap pelaksanaan terbentuk suasana suasana gembira yang hening, atensi yang telah terbuka siap belajar menjadi landasan fokus pada anak-anak untuk mulai meniru contoh yang telah dipaparkan oleh guru, kesiapan melakukan dari pengamatan anak yang siap meniru contoh kemudian mengembangkan stimulus saintifik pada diskusi yang berlangsung merespon pertanyaan pemantik dari guru, tak ada anak yang melakukan apusan kuas diluar arahan, metode ATIK membantu langkah aktivitas lebih sistematis dan membuat anak menikmati setiap kegiatan dengan terukur.

\section{SIMPULAN DAN SARAN \\ A. Simpulan}

Peningkatan keterampilan literasi numerik dan saintifik menuju pengembangan kognitif anak menuju jenjang pendidikan berikutnya dapat dilakukan dengan lebih terarah dengan menggunakan metode ATIK, siswa TK A dan TK B di TK Mutiara Lebah dapat melakukan kegiatan dengan cat air lebih baik, serta mendapat manfaat pengetahuan perbedaan warna yang menjadi pengalaman saintifik. Ketenangan dan proses menir sistematis secara verbal dan aktivitas gerak imajinatif membantu memori anak untuk melakukan tanpa banyak tanya.

\section{B. Saran}

Pembahasan terkait penelitian ini masih sangat terbatas dan membutuhkan banyak masukan, saran untuk penulis selanjutnya adalah mengkaji lebih dalam dan secara komprehensif tentang Peningkatan Kognitif 
melalui Literasi Numerik dan Saintifik dengan Metode Atik pada Kegiatan Cat Air di TK Mutiara Lebah.

\section{DAFTAR RUJUKAN}

Watini, Sri, (2020), Pengembangan Model ATIK untuk Meningkatkan Kompetensi Menggambar pada Anak Taman KanakKanak, Volume 5 Issue 2 (2021) Pages 1512-1520 Jurnal Obsesi: Jurnal Pendidikan Anak Usia Dini, Jakarta

Brown, Rhonda Douglas, (2018), Neuroscience of Mathematical Cognitive Mathematical Cognitive Development; From Infancy Through Emerging Adulthood, Springer, Cincinnati, USA.

Eshach, Haim, (2006), Science Literacy in Primary Schools and Pre-schools, Springer, Dordrecht, Netherlands.

Mc Naughton, Maureen, (2007), The Brush Handbook-Northlight Books, Library of Congress Cataloging, Australia.

Van Leuven, Kristin, (2017), Modern Watercolor, Walter Foster Publishing, Lake Forest USA.

Watini, Sri, (2020), Implementation of Asyik Play Model in Enhancing Character Vale of Early Childhood,Journal of Physics, Vol 1477, IOP Publishing Ltd., Malaysia.
Sunarsi, D. (2016). Pengaruh Minat, Motivasi Dan Kecerdasan Kognitif Terhadap Prestasi Belajar (Studi Kasus Pada Mahasiswa Program Studi S-1 Manajemen. Fakultas Ekonomi. Universitas Pamulang. Thn. Akademik 2015-2016). PROCEEDINGS UNIVERSITAS PAMULANG, 1(1).

Sunasi, D., Kusjono, G., \& Nuryana, I. (2019). Pelatihan Manajemen Penguasaan Kelas Dan Pembuatan Bahan Ajar Bagi Tenaga Pengajar Sukarela Taman Belajar Kreatif Mekarsari.Jurnal Pengabdian Dharma Laksana, 2(1), 41-44.

Wijoyo, H., Handoko, A. L., Santamoko, R., \& Sunarsi, D. (2020). Strategy model for character education through digital media for courses and training participants. Eprosiding pascasarjana universitas negeri gorontalo, 1-8.

Sudarsono, A., \& Sunarsi, D. (2020). Pengaruh Kualitas Pelayanan Dan Varian Produk Terhadap Keputusan Pembelian Pada Laboratorium Klinik Kimia FarmaBintaro. Value: Jurnal Manajemen dan Akuntansi, 15(1), 16-26. 